\title{
Enseñar la historia por medio de las artes visuales. La violencia en Colombia 1948-2002*
}

\author{
Javier Andrés Villamil Roa** \\ Recibido: 7 de febrero de 2017 \\ Enviado a pares evaluadores: 10 de febrero de 2017 \\ Aprobado por pares evaluadores: 22 de marzo de 2017 \\ Aprobado por comité editorial: 17 de mayo de 2017 \\ D0l: 10.22395/csye.v6n11a3
}

\section{RESUMEN}

El artículo se propone un análisis interdisciplinar entre las artes visuales, la historia nacional y la enseñanza de la misma, específicamente el problema de la violencia en Colombia (1948-2002). A partir de referentes pedagógicos como el constructivismo y la teoría crítica se desarrolla una propuesta curricular encaminada a enseñar los procesos de violencia en Colombia con base en la apreciación, análisis, lectura y creación de imágenes artísticas, con el objetivo de promover aprendizajes más completos sobre la historia del conflicto colombiano, así como del patrimonio artístico nacional. Los principales materiales usados y los fundamentos de esta investigación se pueden consultar también en http:// clioyotrasmusas.blogspot.com/

Palabras clave: historia, didáctica de la historia, artes visuales, metáfora visual, conflicto armado, las tres violencias.

Artículo resultado de la investigación concluida en el año 2013 en el Instituto Pedagógico Nacional, como trabajo de grado para el Departamento de Ciencias Sociales de la Universidad Pedagógica Nacional.

** Licenciado en Ciencias Sociales de la Universidad Pedagógica Nacional. Correos electrónicos: javiervllml@ gmail.com, small.vil@hotmail.com 


\section{Teach history through the visual arts. Violence in Colombia 1948-2002}

\section{ABSTRACT}

The article proposes an interdiscipli- images, with the aim of promoting more nary analysis between the visual arts, the complete learning about the history of the national history and the teaching of the Colombian conflict as well as the national same, specifically the problem of violence artistic heritage. The main materials used in Colombia (1948-2002). Based on peda- and the basis of this research can also be gogical references such as constructivism found at: http://clioyotrasmusas.blogspot. and critical theory, a curricular proposal is developed to teach the processes of violence in Colombia based on the appreciation, analysis, reading and creation of artistic com/

Key words: History, didactics of history, visual arts, visual metaphor, armed conflict, the three violence. 


\begin{abstract}
Ahora consideramos clave que desde la reflexión y el arte se mire en común el conflicto armado, que desde hace más de 50 años oprime, como una pesada carga, a la mayoría de la población. Colombia es una mezcla explosiva: sectores dirigentes que con pocas excepciones son rapaces, sin conciencia de país, que casi no han permitido relevos en estos 200 años, y sectores de la población que buscan caminos propios pero que aún no han logrado consolidar del todo propuestas alternativas que marquen nuevas rutas en el desarrollo armónico y equitativo para el país. Es fundamental para Colombia reflexionar sobre los problemas que nos afectan, sus raíces y posibles salidas, y hacerlo a partir de la creación posibilita tener miradas diversas sobre los hechos.
\end{abstract}

OSPINA, 2010

\title{
Introducción
}

El conocimiento histórico es básico para cualquier sociedad; permite entender el porqué, cómo, cuándo y dónde de los acontecimientos que configuran el presente, mantenerlo como eje educativo nos previene sobre la necesidad de entender el pasado para reflexionar sobre nuestro presente y planear el futuro. No obstante, la investigación y enseñanza de la Historia no deben limitarse a la narración de los hechos, pues esta narración presenta la historia de manera estática, aburrida, distante -en especial para los estudiantes- que no se cuestiona sobre el presente y contribuye así a reproducir el statu quo.

Sin embargo, dentro de las aulas de las escuelas, colegios e incluso universidades, la enseñanza de la Historia poco ha cambiado en sus contenidos, y aún menos en la manera de enseñar; los maestros suelen caer en el error de la enseñanza memorística, taxonómica, como lo indica el Ministerio de Educacion Nacional-MEN-; se "retoma en muchas ocasiones, nuevamente la enseñanza de la Historia, basada en fechas, y una geografía limitada a la descripción física de los lugares" y todavía se mantiene la dependencia hacia textos escolares en el desarrollo de las clases. Muchos profesores se atreven a usar películas o juegos como forma de atraer la atención de los estudiantes hacia temas históricos y / o para cambiar la rutina, pero, sin los debidos acompañamientos conceptuales, el alumno no percibe unidad y coherencia sino actividades diversas e inconexas sin un horizonte conceptual claro.

En este documento se busca problematizar y proponer alternativas didácticas orientadas a la enseñanza de la historia de forma que permita innovar en la práctica de los docentes. 


\section{Problema de investigación}

¿Cómo vincular las artes visuales a la enseñanza y comprensión del problema de la violencia en Colombia (1948-2002), dentro del aula de una institución de Educación Básica? Este interrogante fue el derrotero mediante el cual se exploró la relación interdisciplinar entre la apreciación y la producción artística, la práctica pedagógica y el conocimiento histórico de Colombia durante la segunda mitad del siglo XX, específicamente el conflicto armado. Se quiere que a través de la producción de obras de arte visual los estudiantes se interesen por la reciente Historia del país y se puedan generar espacios de creatividad, reflexión y pensamiento crítico en el interior del aula.

La enseñanza interdisciplinar entre la historia y las artes aporta una serie de habilidades cognitivas como son la capacidad de análisis, la creatividad, la interpretación crítica, la visión de síntesis y la construcción de una conciencia histórica; además, como opina Hernández (2000, p. 39) "Junto con la Historia, son las experiencias y conocimientos afines al campo de las artes los que más contribuyen a configurar las representaciones simbólicas portadoras de los valores, que los detentadores del poder utilizan para fijar su visión de la realidad".

Es bien conocido el refrán "una imagen vale más que mil palabras". Pues bien, existe gran variedad de imágenes producidas por artistas visuales, que reflejan, a su manera, la realidad del país en su largo recorrido de violencia que aún hoy sigue presente. Las artes visuales, como medio de expresión, son también una forma de denuncia ante las injusticias de nuestra cotidianidad, y ofrecen una zona de reflexión quem al ser vinculada al espacio académico de la escuela, constituye una posibilidad de entender el mundo, y coadyuva a formar sujetos sociales conscientes de su entorno, con capacidad para criticarlo y transformarlo en beneficio común.

Todas las obras de arte tienen como finalidad expresar algo que no se limita al artista sino que inevitablemente involucra a su sociedad; poseen orígenes y propósitos culturales y sociales en tanto que participan en la construcción de la realidad, no solo representándola sino a modo de crítica y propuesta, resaltando procesos y actores que son invisibilizados dentro de los discursos oficiales, como dijo el artista alemán Paul Klee "el arte no reproduce lo visible, vuelve visible" (Wajcman, 2001); de esta manera fue como Alejandro Obregón, Débora Arango, Pedro Alcántara, entre otros, se dedicaron a hacer ver las atrocidades de la violencia "condenando al violento y mostrando compasión por el violentado" (Medina, 1999, p. 11). 


\section{Metodología}

El cuerpo íntegro del proyecto es fruto de un enfoque cualitativo y del uso de herramientas de la investigación acción educativa que permitieron entender el contexto de la población, sus necesidades y la forma de intervenir para ayudar a solucionar problemáticas en los procesos educativos institucionales. El proyecto fue construido de manera cíclica y dialógica dando pie a reflexionar sobre la teoría y las prácticas educativas.

La implementación de la propuesta didáctica tuvo lugar en el Instituto Pedagógico Nacional (IPN), en el espacio "taller de historia", con estudiantes de $8 .^{\circ}$ y $9 .^{\circ}$ grado durante el tercer trimestre académico del año 2012; en este período se pusieron en práctica las actividades de interpretación de imágenes y creación de arte relacionadas con el problema del conflicto armado colombiano. El material utilizado y algunos fundamentos de la presente investigación pueden consultarse en la web http://clioyotrasmusas.blogspot.com/

En razón de que la intención de este proyecto es desarrollar una alternativa en los procesos de la enseñanza-aprendizaje de un período histórico colombiano a través de la expresión visual y la interpretación de tales expresiones, impulsando el pensamiento crítico y reflexivo, fue necesario apropiarse de referentes pedagógicos presentes en corrientes contemporáneas, tales como la pedagogía crítica y las teorías constructivistas, en lo que Joe Kincheloe llama constructivismo crítico:

El constructivismo se relaciona con la teoría crítica, en la medida en que aplica la toma de conciencia de cada uno para construir la relación entre su propia identidad y las representaciones sociales sobre "el mundo" (...) Esta toma de conciencia permite entender cómo las opiniones políticas, las creencias religiosas, las cuestiones relacionadas con el género, las manifestaciones simbólicas de carácter visual o las perspectivas educativas que cada uno tiene han sido influenciadas por concepciones dominantea (Hernandez, 2000, p. 108)

Resulta necesario retomar la teoría socio cultural de Vygotsky en la cual se enfatiza que el conocimiento es una construcción social; dado que vivimos en un sociedad, construimos nuestra visión de la realidad a partir de las interacciones entre sujetos; el conocimiento es construido entre el niño y el medio sociocultural que lo rodea; en palabras de Peter McLaren (1984, p. 206) el conocimiento "es producto del acuerdo o consentimiento entre los individuos que viven relaciones sociales particulares".

Así, pues, se espera contribuir a formar al estudiante en crítica del arte, crítica social y critica histórica, acompañados de la apreciación artística y verbal. 


\section{Artes visuales, metáfora visual y las tres violencias}

Antes de iniciar el análisis propiamente dicho, es conveniente precisar en qué sentido se entienden estos tres conceptos.

\section{Artes visuales}

Dado que el concepto arte visual resulta ambiguo, pues puede aplicarse a diversas manifestaciones artísticas con propiedades visuales, en la presente investigación es usado para referirse a obras de arte que son fundamentalmente imágenes pre-construidas y estáticas, es decir, sin movimiento, cuya funcionalidad es reproducir y crear cultura a través de referentes semióticos y estéticos que dan lugar a múltiples interpretaciones. Esta forma de arte se caracteriza por contener y presentar metáforas visuales de las ideas que quiere expresar el artista.

En esencia, se trata de obras de arte expresadas en las técnicas de dibujo, pintura, fotografía y caricatura.

\section{Metáfora visual}

Es un recurso semiótico que permite, de manera rápida y sencilla, hacer comprensible una idea por medio de una imagen icónica. Las artes visuales representan el mundo a través de la elaboración metafórica, construyen imágenes que logran concretar un poder de lenguaje estructurado entre significados y significantes, que con la interacción del observador generan un diálogo en cuyo lugar se construye conocimiento. En las metáforas visuales, lo verbal encaja en lo visual de modo que se construyen significados confirmando características visuales como el color, las formas, el estilo, etc., con base en la experiencia cultural. La capacidad de entender y crear metáforas está netamente ligada a procesos cognitivos complejos como son la imaginación y la interpretación, habilidades importantísimas de incentivar en los procesos educativos.

\section{Las tres violencias y la búsqueda de la paz. 1948-2002}

La guerra no tendrá fin si no se admiten prescripciones para las violencias del pasado.

RENAN, 1992

Nuestro país, como muchos otros de América Latina, ha tenido que pasar por un largo recorrido de conflictos armados en su búsqueda por consolidar un Estado-Nación y lograr una democracia formal. Sin embargo, a diferencia 
de otros países del Continente, en Colombia no se ha cerrado el capítulo de violencia generalizada que aparece como un continuum de nuestra sociedad y con características que la presentan como única respecto a otras, como si se tratara de una "violencia endémica". Por supuesto que en Colombia hay mucho más que actos violentos y heridas sin cerrar, pero es innegable que la "presencia histórica de la guerra tiene vínculos determinantes con la construcción de nuestro imaginario de nación" (Sánchez, 2003, p. 37), y que aún hoy es preciso reflexionar sobre el fenómeno social que significa la violencia en nuestro país.

Una manera de contribuir a la reflexión es caracterizando períodos según los procesos que se han generado, teniendo en cuenta los cambios y continuidades propios de una época. Para el caso concreto de esta investigación se ha tomado un período que comienza con el asesinato del líder liberal Jorge Eliécer Gaitán el 9 de abril de 1948, acto catalizador de la guerra, hasta el fin del período presidencial del conservador Andrés Pastrana Arango, quien dejó el poder después de un intento infructuoso y desprestigiado de encontrar una salida negociada al conflicto armado.

Tres etapas componen el período, según la clasificación que propone Álvaro Medina:

1. La violencia bipartidista, que se inicia en 1947 y cierra, al menos simbólicamente, al ser abatidos por el ejército Sangrenegra y Efraín González. El primero, cuyo verdadero nombre era Jacinto Cruz Usma, cayó en abril de 1964, y el segundo, en junio de 1965. Los dos fueron jefes de cuadrillas dedicadas al bandolerismo, luego del pacto que sellara la reconciliación de los partidos Conservador y Liberal, origen del Frente Nacional (1958-1974), pacto que dejó sin norte político a los combatientes de ambos bandos que habían hecho de la beligerancia un modo de vida.

2. La violencia revolucionaria, que tiene sus inicios en 1959 con la aventura guerrillera del MOEC (Movimiento Obrero Estudiantil y Campesino), que abortó desde los primeros enfrentamientos con el ejército. Otros grupos aparecieron con el tiempo, de modo que la presión de la izquierda alzada en armas no ha cesado desde entonces.

3. La violencia narcotizada, que se manifiesta con la consolidación de los carteles de la droga, cuya ahogante presencia logró penetrar todos los estratos de la sociedad colombiana. El sicariato y el paramilitarismo, máquinas de muerte que de preferencia actúan contra el ciudadano inerme, quedaron instaurados (Medina, 1999, p. 19).

Son más de cincuenta años en los cuales han cambiado las particularidades del conflicto, pero no su esencia violenta, donde han ido y venido distintos 
gobiernos; ha crecido la población desplazada; han cambiado la tecnología de la guerra y el negocio de la guerra; han sido abatidos jefes guerrilleros; se han desmovilizado o desaparecido grupos armados y políticos, a la vez que se han integrado otros, haciendo más complejo el espectro de actores que rivalizan en el teatro llamado Colombia.

\section{Algunas aproximaciones a la relación artes visuales-historia-educación}

\section{Las artes como testimonio de la historia}

El arte visual ha registrado instantes, movimientos, acontecimientos, alegrías, penas, dramas en muchos contextos y épocas; emplear el registro de un instante vitalizado por la acción social puede arrojar información sobre costumbres, hábitos, tendencias, modas, que responden a esos cuadros complejos dibujados por la dinámica social que se fijan visualmente en la memoria y despiertan evocaciones de añoranza, deseos y variadas sensaciones, desde las más bellas hasta las más horrorosas y lúgubres, unas y otras son imposibles de borrar y cobran significados diversos (Ortiz, 2007).

Históricamente la humanidad ha sentido la necesidad de entender su entorno y las cosas que lo componen; así, desarrolló sistemas de comunicación, primero, basados en sonidos que se convirtieron en palabras, seguidamente aprendieron a representar su realidad con imágenes, y con el tiempo estos sistemas, estas técnicas se hacen cada vez más complejos; según aumentó el conocimiento del mundo, la técnica de elaboración de imágenes evolucionó en un sentido más realista y su funcionalidad cambió según la época y la cultura: como lenguaje escrito para los antiguos egipcios; como representación de seres sagrados o alegorías de estética y poder; y desde el siglo XX como entretenimiento para el público a través de medios audiovisuales, pero lo que no ha cambiado es su facultad de significar ideas abstractas u objetos reales dentro de la compleja historia humana.

Además de ser un mecanismo para entender el mundo, la técnica se ha usado para recordar, es de destacar la relación entre arte / técnica ${ }^{1}$ y memoria, pues en principio el arte está ligado a la memoria y es un auxilio para no olvidar, como es el caso de la mnemotécnica o Ars memoriae usada por antiguos y contemporáneos como método de aprendizaje y para mantener vivo el pasado reproduciendo la estructura cultural de una sociedad, con sus tradiciones, creencias y sistemas

\footnotetext{
Recordando que arte y técnica tienen el mismo origen etimológico y se refieren a un saber hacer concreto.
} 
de valores, todos heredados de tiempos anteriores a través de manifestaciones artísticas como la literatura, la poesía, la música y, por supuesto, las artes visuales. Básicamente, la función de las artes a través de la historia cultural humana ha sido y continúa siendo la tarea de la "construcción de la realidad" (Efland, 2004).

Arte y memoria se han complementado desde antaño para ayudar a la comprensión y reproducción del mundo cultural, como diría Iván David Ortiz:

Mnemosine, hija de Urano y Gea es decir, del cielo y la tierra, fue la que parió de Zeus las nueve musas que le permitieron a los órficos griegos, a través del recuerdo, acceder a las memorias arcanas y "'romper las ataduras de Leto" (Ortiz, 2008, p. 88).

Clío es la musa de la Historia y, por ende, la historia nació como arte, aunque después para la sociedad moderna se convirtió en ciencia, víctima de la resignificación que se les dio al arte y la ciencia, guiados por la razón y los paradigmas positivistas propios de la Modernidad. Con esto se destaca que las artes y los objetos del arte son también objetos de la memoria, huellas del pasado que nos llevan a recordar hechos, procesos y personajes de la historia: "el artista por su parte, quiere aludir a la memoria, mostrar la memoria del hombre, del espacio, de lugares, etc."2 . Los monumentos, por ejemplo, son objetos, pero no cualquier tipo de objeto, pues no tienen una funcionalidad instrumental sino que están para representar algo que no es el objeto mismo y que posee un significado social, digno de conmemorar, incluso, exaltar; además, ocupan lugares públicos para que la sociedad rememore una parte esencial de la cultura misma. De igual forma ocurre con la pintura, la música y la literatura que a lo largo de la historia se han conservado y nos dan un testimonio de cómo fue el pasado y qué podemos aprender de este, es decir, nos permite hacer una reflexión histórica.

\section{La obra de arte como metáfora de realidades nacionales}

¿Y si las obras-del-arte que se miran tuvieran también el efecto de hacernos mirar? (...) Esto debería llevar a concebir de otro modo lo que es una obra. Al dar antaño una "imagen" del mundo, al reflejar, lo que daba era por fuerza una interpretación del mundo. A la manera de Marx, ahora habría que decir que el arte pasaría así de la reflexión al acto: no ya dar a ver una interpretación del mundo, sino cambiar nuestra manera de ver el mundo, transformar nuestra mirada, hacerla-ver (Wajcman, 2001, p. 35).

2 Opinión de la artista colombiana María Patricia Bravo, citado en Gaitán Tobar, A. (1999). El arte en la era de los ciegos. En A. Medina, Arte y violencia en Colombia desde 1948. Bogotá. Norma. 
Para entender una obra de arte es necesario conocer el contexto histórico del cual proviene; asimismo, para entender un período histórico nos podemos remitir a conocer las obras de arte que permanecen desde su creación; el arte de cada época determina -por lo menos en parte- la interpretación del pasado.

Siendo las obras de arte, obras de la memoria, también son testimonios del pasado y fuentes para un análisis histórico de un fenómeno social como es la violencia en nuestro país durante la última mitad del siglo XX, y no son pocos los creadores de cultura, es decir, los artistas colombianos que han reflejado en sus obras el conflicto armado colombiano, "hay artistas cuya sensibilidad los inclina a tratar constantemente temas sociales y políticos; otros, por el contrario, tienden a ignorarlos" (Medina, 1999, p. 15); sin embargo, no es fácil ignorar la situación del país e incluso tampoco es sensato hacerlo, pues si pretendemos ocultar lo que pasa en nuestra sociedad, caemos en el discurso que legitima las injusticias que hemos vivido directa o indirectamente, como en un fragmento de Cien años de soledad, la obra de Gabriel García Márquez en donde las autoridades interrogadas por las desapariciones y crímenes que vivía el pueblo respondían "En Macondo no ha pasado nada, ni está pasando, ni pasará nunca. Este es un pueblo feliz".

Discursos como estos deben ser desmentidos y denunciados como labor de toda la sociedad y especialmente de los que tienen medios y maneras creativas para hacerlo; así pues, "el artista funge de sociólogo o de historiador contestatario, pero en verdad actúa como el exorcista que desea espantar los espíritus negativos que nos rodean" (Medina, 1999, p. 104), puesto que la violencia es como un fantasma recurrente que atormenta el país, no le permite dormir y quiere quitarle la oportunidad de soñar un futuro mejor. Sin embargo, los primeros pasos para superar esta situación son denunciar, reflexionar y caracterizar la violencia que vivimos de modo que podamos proponer un país diferente.

\section{Artes visuales: un puente hacia el conocimiento sociocultural}

La finalidad de la pedagogía y el arte es la de propiciar la capacidad creativa a partir del desarrollo de un pensamiento reflexivo, crítico y autónomo del sujeto.

(Nohora Patricia Aríza

Revista Internacional Magisterio \# 49, 2011)

La educación en ciencias sociales constituye el núcleo de aprendizaje cultural de la escuela -segundo espacio de socialización después de la familia- en donde se espera formar sujetos sociales con conocimientos científicos y saberes axiológicos; por otro lado, las artes visuales son un mecanismo de producción y 
reproducción cultural; por ello integrar ambas áreas de modo transversal en los contenidos curriculares contribuye a innovar en las estrategias de enseñanza habituales para formar seres humanos capaces de convivir pacíficamente, a la vez que aportan al desarrollo cognitivo de los mismos, como lo indica López (2011, p. 20), el arte ayuda al "desarrollo de habilidades y competencias vinculadas también al autoconocimiento (ser), a la relación y comunicación por diferentes medios con sus semejantes (convivir), a la generación de pensamiento amplio y a la aplicación de lo aprendido en muchos otros campos (conocer)".

Como explica Arthur Efland (2004, p. 25) dado que las obras de arte no pueden comprenderse alejadas del contexto social y cultural en el que fueron creadas, es preciso

Entenderlas en cuanto a sus orígenes y propósitos culturales y sociales, entonces tendría sentido integrar el conocimiento de la obra de arte en materias como las ciencias sociales y la historia, en las que se ofrece un conocimiento paralelo de la cultura y la sociedad.

Son varios los autores que han reflexionado acerca de la tarea de integrar las artes al currículo (tabla 1), y han dejado como resultado diversas opciones teórico-prácticas entre las que se destacan las versiones de "cultura visual", "desarrollo cognitivo" y "artes integradas", las cuales, -sin demeritar las otras opciones- enfatizan en la interpretación de los mensajes políticos, históricos, culturales, mediados por las imágenes.

Entre las ventajas del uso de imágenes para complementar el aprendizaje de un tema, es importante decir que promueven la capacidad para construir interpretaciones desde una edad relativamente temprana, permitiendo que el estudiante reconozca las imágenes y construya significados por medio de la observación, sin necesidad de descodificar números o letras; además, toda obra de arte visual es una obra abierta que se completa en la interacción de artistaobra-espectador, es decir, entrañan una dimensión dialógica, que impulsa la imaginación, creatividad y búsqueda de respuestas. "La imagen nos place, ¿Por qué habríamos de oponernos al instruir deleitando?” (Carretero, 1997, p. 69).

Tabla 1. Resumen de las versiones de la educación artística en la actualidad (Juanola \& Calbó, 2004)

\begin{tabular}{|c|c|c|}
\hline Versión & Objetivos principales & Tipo de contenido \\
\hline $\begin{array}{l}\text { DBAE } \\
\text { (Educación } \\
\text { Artística basada } \\
\text { en las disciplinas) }\end{array}$ & $\begin{array}{l}\text { - Producir arte de calidad } \\
\text { - Ver y apreciar el arte }\end{array}$ & $\begin{array}{l}\text { - Habilidades, imaginación, Sensi- } \\
\text { bilidad, técnica. } \\
\text { - Cualidades formales y expresivas } \\
\text { del arte. } \\
\text { - Cuestiones de valor del arte: be- } \\
\text { lleza, verdad, función... }\end{array}$ \\
\hline
\end{tabular}




\begin{tabular}{|c|c|c|c|}
\hline Versión & Objetivos principales & \multicolumn{2}{|c|}{ Tipo de contenido } \\
\hline & $\begin{array}{l}\text { - Comprender el contexto cul- } \\
\text { tural del arte } \\
\text { - Comprender el valor del arte }\end{array}$ & & \\
\hline $\begin{array}{l}\text { CULTURA } \\
\text { VISUAL }\end{array}$ & $\begin{array}{l}\text { Descodificar los mensajes } \\
\text { políticos (identidad, género, } \\
\text { raza, clase...) mediados por } \\
\text { las imágenes, en la cultura } \\
\text { popular y en las bellas artes. }\end{array}$ & \multicolumn{2}{|c|}{$\begin{array}{l}\text { - Cuestiones de clase, género, raza, } \\
\text { cultura... } \\
\text { - Interpretación de imágenes } \\
\text { - Crítica }\end{array}$} \\
\hline $\begin{array}{l}\text { SOLUCIÓN } \\
\text { CREATIVA DE } \\
\text { PROBLEMAS }\end{array}$ & $\begin{array}{l}\text { Resolver problemas prácticos } \\
\text { de maneras y formas } \\
\text { - técnicamente eficaces y } \\
\text { - estéticamente satisfactorias }\end{array}$ & \multicolumn{2}{|c|}{$\begin{array}{l}\text { - Forma y material / técnica } \\
\text { - Función, belleza y forma } \\
\text { - Conceptualización, análisis, pro- } \\
\text { blematización, creatividad, diver- } \\
\text { gencia. }\end{array}$} \\
\hline $\begin{array}{l}\text { AUTOEXPRESIÓN } \\
\text { CREATIVA }\end{array}$ & $\begin{array}{l}\text { Desarrollar la experiencia per- } \\
\text { sonal, la percepción individual } \\
\text { y la respuesta creativa, origi- } \\
\text { nal y propia. }\end{array}$ & \multicolumn{2}{|c|}{$\begin{array}{l}\text { - Creatividad } \\
\text { - Emoción } \\
\text { - Expresión } \\
\text { - Flexibilidad }\end{array}$} \\
\hline $\begin{array}{l}\text { PREPARACIÓN } \\
\text { PARA EL } \\
\text { TRABAJO }\end{array}$ & $\begin{array}{l}\text { Desarrollar actitudes y destre- } \\
\text { zas necesarias para el futuro } \\
\text { profesional de los alumnos en } \\
\text { cualquier campo }\end{array}$ & \multicolumn{2}{|c|}{$\begin{array}{l}\text { - Iniciativa y creatividad/planifica- } \\
\text { ción } \\
\text { - Imaginación } \\
\text { - Destreza manual } \\
\text { - Trabajo en equipo (algunas artes) } \\
\text { - Relacionar y comunicar ideas }\end{array}$} \\
\hline $\begin{array}{l}\text { DESARROLLO } \\
\text { COGNITIVO }\end{array}$ & $\begin{array}{l}\text { Desarrollar formas de pensa- } \\
\text { miento complejas y sutiles, más } \\
\text { allá de leer, escribir, contar y } \\
\text { calcular. }\end{array}$ & $\begin{array}{l}\text { Percepción } \\
\text { Experiencia } \\
\text { estética }\end{array}$ & $\begin{array}{l}\text { Afectivo / cognitivo } \\
\text { Concreto / abstracto } \\
\text { Emocional / racional } \\
\text { Manual / mental } \\
\text { Fantasía / función } \\
\text { Juego / Tarea }\end{array}$ \\
\hline $\begin{array}{l}\text { MEJORA } \\
\text { ACADÉMICA } \\
\text { GLOBAL }\end{array}$ & $\begin{array}{l}\text { Desarrollar las capacidades en } \\
\text { las materias consideradas } \\
\text { básicas, con la ayuda de lo ca- } \\
\text { racterístico del arte }\end{array}$ & \multicolumn{2}{|c|}{$\begin{array}{l}\text { No se describen en particular, se } \\
\text { dan por supuestos. }\end{array}$} \\
\hline $\begin{array}{l}\text { ARTES } \\
\text { INTEGRADAS }\end{array}$ & $\begin{array}{l}\text { El arte sirve a cualquiera o a } \\
\text { todas las otras disciplinas del } \\
\text { currículum }\end{array}$ & \multicolumn{2}{|c|}{$\begin{array}{l}\text { - Arte para la Historia } \\
\text { - Relaciones entre el conjunto de las } \\
\text { artes } \\
\text { - Temas interdisciplinares (Meta- } \\
\text { morfosis, arquitectura...) } \\
\text { - Solución de problemas (proyectos) }\end{array}$} \\
\hline
\end{tabular}


El análisis de obras de arte visual, es decir, de metáforas visuales, ayuda a comprender el conocimiento social. Una pintura, por ejemplo, nos ofrece información de la época del artista, así como del entorno, las prácticas, la estructura social, entre otros. La obra de arte "influye en su momento, pero perdura a través del tiempo ejerciendo una influencia directa sobre muchas generaciones posteriores" (Carretero, 1997, pág. 86). Particularmente, en las ciencias sociales la podemos usar como puente para la construcción de conceptos y categorías, resaltando los aspectos ideológicos, político, sociales, culturales, temporales y geográficos representados en las imágenes de obras artísticas; por lo tanto, el fin de integrar referentes visuales a los contenidos de las ciencias sociales es "contribuir a la comprensión del paisaje social y cultural en el que habita cada individuo" (Efland, 2004, pág. 229) por medio de la observación, interpretación y diálogo con las elaboraciones metafóricas presentes en la tradición cultural de nuestra sociedad.

\section{Leyendo imágenes}

Cuando leemos imágenes -de hecho, imágenes de toda clase, sean pintadas, esculpidas, fotografiadas, construidas o en movimiento-les agregamos la temporalidad propia de la narrativa. Extendemos a un antes y un después lo que está limitado por un marco, y mediante el arte de contar historias damos a la imagen inmutable una vida inagotable e infinita (Manguel, 2003, p. 25).

Para el proceso de interpretación de metáforas visuales propias de las obras a usar, es importante prever cómo serían aceptadas por parte de los estudiantes, y cómo repercute su implementación en el proceso de aprendizaje de un tema determinado, así pues, se ponen a consideración las contribuciones de autores como Maite Pró y José Rodríguez Diéguez, quienes con base en sus experiencias proponen criterios para enseñar con y a través de imágenes.

En la tabla 2, se proponen algunas variables que a la hora de mirar e interpretar una imagen juegan un rol importante en la mente de los estudiantes; entre las mencionadas se destacan: legibilidad / ilegibilidad, y mensaje pansémico / mensaje monosémico en tanto que denotan que un educador puede hallar múltiples interpretaciones a la hora de trabajar con imágenes, así como la dificultad por parte de algunos estudiantes en la lectura del mensaje visual.

En comparación, la tabla 3 nos muestra un cuadro basado en la observación que hace Diéguez J. R. (1991), en relación con los niveles de análisis que plantea Panofsky (1972) acerca del contenido temático de una obra de arte. Aunque para el historiador del arte Erwin Panofsky existen tres niveles de acercamiento, José 
Diéguez los resume en dos, el primero de los cuales corresponde a la descripción pre-iconográfica, y el segundo, al análisis iconográfico.

Ambas tablas complementan las formas y maneras que debemos tener en cuenta como docentes a la hora de acercarnos a una obra de arte visual; además, proporcionan una guía para emprender acciones didácticas, pues los estudiantes también se deben relacionar con estos conceptos en el proceso de lectura de imágenes.

Finalmente, la tabla 4 se pregunta cómo los estudiantes incorporan a la comprensión de sus conocimientos la imagen que acompaña el proceso educativo. Esta tabla es importante, en tanto que ofrece una perspectiva psicológica de las acciones que un estudiante emplea para leer una imagen y cómo influye en el aprendizaje.

\section{Tabla 2. Variables características que intervienen en el análisis estructural de un mensaje icónico (Pró, 2003, p. 33)}

\begin{tabular}{|l|l|}
\hline Legibilidad & Ilegibilidad \\
\hline $\begin{array}{l}\text { Facilidad en la percepción de la lectura } \\
\text { y en la interpretación del mensaje visual }\end{array}$ & Dificultad en la lectura y en la interpretación \\
\hline Simplicidad & Complejidad \\
\hline $\begin{array}{l}\text { Tiene un carácter directo, libre de com- } \\
\text { plejidades }\end{array}$ & $\begin{array}{l}\text { Diversidad visual a causa de la presencia de } \\
\text { unidades de carácter secundario }\end{array}$ \\
\hline Economía & Profusión \\
\hline $\begin{array}{l}\text { Muy pocos elementos, los justos para } \\
\text { comprender el mensaje visual. }\end{array}$ & $\begin{array}{l}\text { Demasiados elementos que se presentan de } \\
\text { manera atiborrada y recargada. }\end{array}$ \\
\hline Mensaje pansémico & Mensaje monosémico \\
\hline Abierto a diversas interpretaciones. & $\begin{array}{l}\text { Encaminamiento hacia una interpretación } \\
\text { única. }\end{array}$ \\
\hline Originalidad & Vulgaridad \\
\hline Enfoque más creativo, diferente & Presentación habitual, sin cambios \\
\hline Información máxima & Información mínima \\
\hline $\begin{array}{l}\text { El mensaje contiene amplitud informa- } \\
\text { tiva. }\end{array}$ & $\begin{array}{l}\text { Pocos elementos integrantes del mensaje vi- } \\
\text { sual }\end{array}$ \\
\hline Coordinación imagen-texto & Descoordinación imagen-texto \\
\hline Estructura unitaria del texto y la imagen. & Se dan dos mensajes yuxtapuestos \\
\hline Denotación & Connotación \\
\hline $\begin{array}{l}\text { El texto apoya la percepción de los aspec- } \\
\text { tos presentes en la imagen }\end{array}$ & $\begin{array}{l}\text { El texto facilita la interpretación subjetiva } \\
\text { de la imagen }\end{array}$ \\
\hline
\end{tabular}


Tabla 3. Análisis del contenido temático de una obra de arte. Basado en la observación que hace (Dieguez J. R., 1991) en relación de los niveles de análisis que plantea (Panofsky, 1972)

\section{Descripción pre iconográfica}

1. Contenido temático natural o primario: pretende la simple identificación de formas puras como representaciones de objetos naturales según una tipología concreta de medios de expresión:

- Realidad perceptiva, sea en un sentido estricto y cuasi fotográfico, sea mediante un tratamiento conceptualizado de dicha realidad.

- Realidad subjetiva, que supone la respuesta personal a una experiencia elaborada mediante una creación y elaboración basada en la acumulación de informaciones que responden a situaciones distintas.

- Comunicación de un orden que expresan las composiciones geométricas.

\section{Análisis iconográfico}

2. Contexto secundario o convencional: exige observar un dato más de la descripción pre iconográfica, detalles de la obra.

3. Significado intrínseco o contenido: interpretación iconográfica o análisis iconológi$\mathrm{co}$, en donde se pretende indagar "aquellos supuestos que revelan la actitud básica de una nación, un periodo, una clase, una creencia religiosa o filosófica, cualificados inconscientemente por una personalidad y condensados en una obra"

Tabla 4. Cómo incide la lectura de la imagen en las estrategias de aprendizaje. (Pró, 2003, pág. 56)

\begin{tabular}{|l|l|l|l|}
\hline $\begin{array}{l}\text { Factores que inter- } \\
\text { vienen en el proceso } \\
\text { de aprendizaje: }\end{array}$ & \multicolumn{1}{|c|}{ Capacidades } & \multicolumn{1}{|c|}{ Soportes } & Procedimientos \\
\hline $\begin{array}{l}\text { Conocimientos pre- } \\
\text { vios } \\
\text { Capacidades intelec- } \\
\text { tuales }\end{array}$ & 1. Observar & $\begin{array}{l}\text { Pauta análisis imagen. } \\
\text { Pauta análisis observa- } \\
\text { Motivación }\end{array}$ & $\begin{array}{l}\text { Análisis de la in- } \\
\text { formación icónica } \\
\text { visual }\end{array}$ \\
\cline { 2 - 4 } $\begin{array}{l}\text { Intereses } \\
\text { Intervención profe- } \\
\text { sor-alumno: interac- } \\
\text { ción }\end{array}$ & $\begin{array}{l}\text { 2. Ordenar y cla- } \\
\text { sificar }\end{array}$ & $\begin{array}{l}\text { Secuenciación de imagen } \\
\text { Ritmo en el lenguaje }\end{array}$ & Ordenación serial \\
\cline { 2 - 5 } zaje... & 3. Representar & $\begin{array}{l}\text { Mapas y plano } \\
\text { Maquetas y esculturas }\end{array}$ & $\begin{array}{l}\text { Representación } \\
\text { icónica }\end{array}$ \\
\hline
\end{tabular}




\begin{tabular}{|c|l|l|l|}
\hline $\begin{array}{c}\text { Factores que inter- } \\
\text { vienen en el proceso } \\
\text { de aprendizaje: }\end{array}$ & \multicolumn{1}{|c|}{ Capacidades } & \multicolumn{1}{|c|}{ Soportes } & Procedimientos \\
\hline & 4. Retener & $\begin{array}{l}\text { Codificación / descodi- } \\
\text { ficación } \\
\text { Mnemotécnicas figura- } \\
\text { tivas }\end{array}$ & $\begin{array}{l}\text { Codificación cog- } \\
\text { nitiva de la infor- } \\
\text { mación }\end{array}$ \\
\cline { 2 - 4 } & 5. Interpretar & $\begin{array}{l}\text { Lenguaje grafico a sim- } \\
\text { bólico } \\
\text { Lenguaje simbólico a ges- } \\
\text { tual }\end{array}$ & $\begin{array}{l}\text { Interpretación por } \\
\text { transposición o tra- } \\
\text { ducción }\end{array}$ \\
\hline
\end{tabular}

\section{La experiencia en el Instituto Pedagógico Nacional -IPN-}

El propósito en las primeras clases fue indagar en los conocimientos previos de los estudiantes sobre qué entienden por arte y qué saben del conflicto armado colombiano. Esto se hizo en la primera actividad (anexo A); allí se pudo ver que los estudiantes tienen preconceptos sobre el arte y la situación social del país; así, por ejemplo, manifestaron que el arte es un "lenguaje visual, auditivo, táctil etc., con el que se puede comunicar ideas sentimientos o sueños"; también les otorgan importancia a las actividades artísticas argumentando que están llenas de significados y mensajes. Asimismo, identifican artistas visuales reconocidos como Pablo Picasso, Leonardo da Vinci, aunque en el ámbito nacional solo nombran a Fernando Botero como único artista visual conocido. En cuanto al conflicto armado nacional, prácticamente ninguno lo desconoció, aunque la mayoría argumentó que ni su familia ni ellos han sido directamente afectados por este; gran parte de lo que conocen sobre este problema lo han aprendido en el colegio y a través de la televisión ya sea noticias o telenovelas nacionales. Identifican problemáticas sociales como la pobreza, la corrupción, la discriminación, y saben de actores armados como el ejército, los paramilitares y la guerrilla, aunque suelen confundirlos entre sí.

En otra actividad se les pidió que expresaran de manera gráfica lo que entienden del conflicto armado, después de una explicación previa y la presentación de fotos, pinturas y caricaturas de artistas colombianos que tratan el tema. En este ejercicio los estudiantes dibujaron diversas escenas, algunas estaban acompañadas de un párrafo en el que explicaron o complementaron el dibujo hecho, a modo de reflexión e, incluso, criticando las acciones de los gobernantes, políticos y policía que se ven envueltos en irregularidades o abuso de poder (anexo B).

Conflicto armado... una "realidad" en la que vivimos desde hace mucho tiempo, en donde la policía abusa del resto en el nombre de la "libertad", en 
donde algo llamado "libre pensamiento" o "libertad de expresión" no existe, en donde todo se resuelve con violencia, en donde un hombre roba un pan para "sobrevivir" es un delito, pero si un político roba millones al estado son "negocios". Cuando se tiene un arma en manos, se pierde parte de la conciencia (Alejandra Hernández, estudiante grado 8-02, IPN).

Durante las siguientes clases, la principal actividad fue el análisis de imágenes; en un primer ejercicio se les proporcionaron dos imágenes del artista polaco Pawel Kuczynski (anexos C y D) conocido por su interpretación satírica del mundo contemporáneo, de las que debían seleccionar una. Primero, se les pidió a los estudiantes que hicieran una descripción pre iconográfica, es decir, identificando los personajes, formas, objetos y colores de la imagen; seguidamente tenían que hacer un análisis de la iconografía presente, interpretando la situación y el mensaje que el artista posiblemente pretende dar, para generar, además, una opinión sobre esta. Después de este primer ejercicio hubo una clase exclusiva para enseñarles a los estudiante cómo leer una imagen, teniendo en cuenta parámetros como monosemia / polisemia, iconicidad / abstracción, denotación / connotación.

Esto se pudo constatar en los trabajos finales donde debían presentar una obra visual, hecha por ellos mismos tomando como referencia las imágenes vistas y las lecturas trabajadas durante las clases. En estos trabajos se evidenció la evolución conceptual y de expresión gráfica que se generó en los estudiantes; al final usaron diferentes conceptos y categorías del conflicto como el bipartidismo (anexo E), la violencia narcotizada, el desplazamiento forzado y los falsos positivos; involucraron más detalles en sus ilustraciones usando también diversos símbolos para construir el mensaje visual; algunos retomaron lecturas donde se manifestaban las relaciones entre el fútbol y el narcotráfico; otros acudieron a la búsqueda de la paz que el país inició en octubre de 2012 con los diálogos entre el gobierno y las FARC (anexos F y G); una de las estudiantes escribió frente a su dibujo:

Los políticos invierten mucha plata en guerra pero dejan a un lado la salud, la educación y el trabajo, ponen distractores como la televisión (novelas y concursos). Además, las personas inocentes asesinadas por militares para que suban de cargo, solo se invierte plata para armas (Alejandra Hernández, estudiante grado 802, IPN).

\section{Conclusiones}

Esta investigación es una reflexión sobre la enseñanza de las ciencias sociales, que propone que en la interpretación del pasado se valoren más las fuentes visuales y, asimismo, en la enseñanza sean un recurso efectivo y recurrente, no para reemplazar las fuentes escritas, sino como complemento que impulse la creatividad de los estudiantes. 
El conflicto armado colombiano es un problema histórico vigente cuyos orígenes y repercusiones aún son materia de investigación y análisis. Esto es necesario iniciarlo desde las instituciones educativas no solo como conocimiento histórico, sino buscando alternativas para su correcta enseñanza / aprendizaje, a fin de reconocer las causas, acontecimiento y actores, así como de mantener viva la memoria de las víctimas.

$\mathrm{El}$ arte es un mediador entre la historia y la enseñanza de la misma, pues, como se ha mencionado a lo largo de este texto, las imágenes contenidas en las obras de arte visuales contribuyen a mejorar la experiencia de aprendizaje, motivando, deleitando, ilustrando conceptos y situaciones, incluso, sensibilizando a los estudiantes sobre un problema crónico como es la violencia del conflicto armado colombiano.

De igual forma, la integración del conocimiento artístico en asignaturas como la historia o las ciencias sociales contribuye a enseñar / aprender desde un enfoque más amplio el conocimiento sociocultural, integrando perspectivas estéticas, ideológicas, políticas, cronológicas, espaciales y axiológicas, y, fundamentalmente, desarrollando la capacidad de observación e interpretación de imágenes. El uso pedagógico de la imagen puede servir para formar estudiantes con más recursos para descodificar la información, es decir, con más posibilidades de comunicación.

Otro aspecto positivo es la posibilidad de que los estudiantes se relacionen con el patrimonio artístico nacional, conociendo los trabajos de artistas colombianos de los cuales muy poco se conoce en la Educación Básica, en especial, las obras que reflexionan sobre la violencia nacional.

Finalmente, es de resaltar que si se acompañan los procesos de interpretación y producción de imágenes sobre la base de una red conceptual que facilite a los estudiantes comprender los conocimientos, a la vez que se contextualizan los contenidos, buscando que los estudiantes entiendan progresivamente el carácter y el valor del conocimiento socio-cultural por medio de actividades de interpretación, creación artística e investigación en ambientes fuera de la institución, se logra modificar las estructuras cognitivas propias de cada estudiante $\mathrm{y}$, consecuentemente, que desarrollen un pensamiento cada vez más complejo que les permita razonar y sentir empatía frente los problemas sociales, buscando generar propuestas en el marco de una salida pacífica al conflicto armado.

\section{Referencias bibliográficas}

Acosta, w. (2000). Las ciencias sociales a través del cine. Bogotá: Magisterio.

Carretero, M. (1997). La historia del arte en el bachillerato. Problemática epistemológica y núcleos básicos. En La enseñanza de las ciencias sociales. Madrid: Visor. 
Díaz, F., \& Hernández, G. (1999). Constructivismo y aprendizaje significativo. México: McGRAW HILL.

Dieguez, J. R. (1978). Las funciones de la imagen en la enseñanza: semántica y didáctica. Barcelona: Gustavo Gili.

Dieguez, J. R. (1991). El comic y su utilización didáctica: los tebeos en la enseñanza. México: Gustavo Gili.

Efland, A. (2004). Arte y cognición. Barcelona: Octaedro-EUB.

Hernández, F. (2000). Educación y cultura visual. Barcelona: Octaedro.

Instituto Pedagógico Nacional. (2012). Documento del área de ciencias sociales. Bogotá.

Juanola, R., \& Calbó, M. (2004). Hacia modelos globales en educación artística. En R. Calaf, \& O. Fontal, Comunicación educativa del patrimonio: referentes, modelos y ejemplos. Oviedo: Ed. TREA.

López, L. J. (2011). Arte y ciencia en la educación básica: hacia un nuevo equilibrio entre el saber y el sentir. Revista Internacional Magisterio \# 49, 16-20.

Manguel, A. (2003). Leer imágenes: una historia privada del arte. Madrid: Alianza.

McLaren, P. (1984). La vida en las escuelas con un comentario sobre el libro y una respuesta del autor más un comentario a la edición revisada. México: Siglo Veintiuno Editores.

Medina, A. (1999). Arte y violencia en Colombia desde 1948. Bogotá: Norma.

Medina, A. (1999). El arte y la violencia colombiana en la segunda mitad del siglo XX. En A. Medina, Arte y violencia en Colombia desde 1948 (pp. 10-119). Bogotá: Norma.

Moreno, C. M. (2002). El arte como elemento creador del pensamiento. Bogotá: CIUP.

Ortiz Palacios, I. D. (2007). El genocidio político contra la Unión Patriótica visto por la prensa escrita 1984-2004. Bogotá: Universidad Nacional de Colombia.

Ortiz Palacios, I. D. (2008). Memoria narrada, narración de una historia: el genocidio político contra la Unión Patriótica. Bogotá: Universidad Nacional de Colombia.

Ospina, W. (2010). Separata: arte y conflicto armado. Recuperado el 20 de abril de 2012, de Revista Número: http://revistanumero.com/index.php?option=com _ content\&task=view\&id=264\& $\underline{\text { Itemid }=39}$

Panofsky, E. (1972). Estudios de iconología. Madrid: Alianza Editorial.

Prats, J. (s.f.). Histodidactica. Recuperado el 2011, de http://www.ub.edu/histodidactica/

Pró, M. (2003). Aprender con imágenes. Incidencia y uso de la imagen en las estrategias de aprendizaje. Buenos Aires: Paidós Ibérica.

Renan, E. (1992). Qu'est- ce qu'une nation. París: Ágora.

Revista Internacional Magisterio \# 49. (2011). Arte y educación. Bogotá: Magisterio.

Sánchez, G. (2003). Guerras, memoria e historia. Bogotá: Instituto Colombiano de Antropología e Historia (ICANH).

Universidad Pedagógica Nacional. (s. f.). Obtenido de http:/www.pedagogica.edu.co

Wajcman, G. (2001). El objeto del siglo. Buenos Aires: Amorrortu. 


\section{Anexo B}

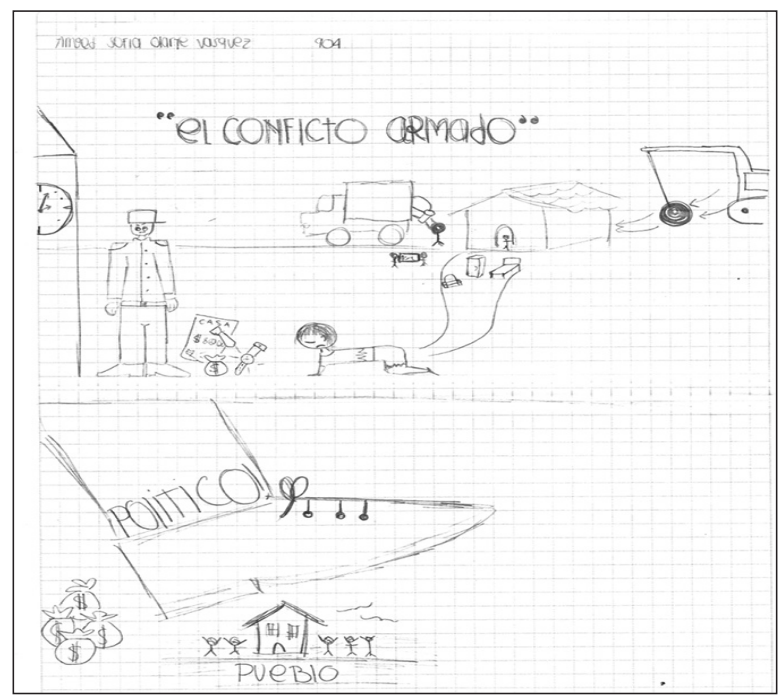

Actividad en clase, estudiante Sofía Olarte, 9-04, IPN

\section{Anexo C}

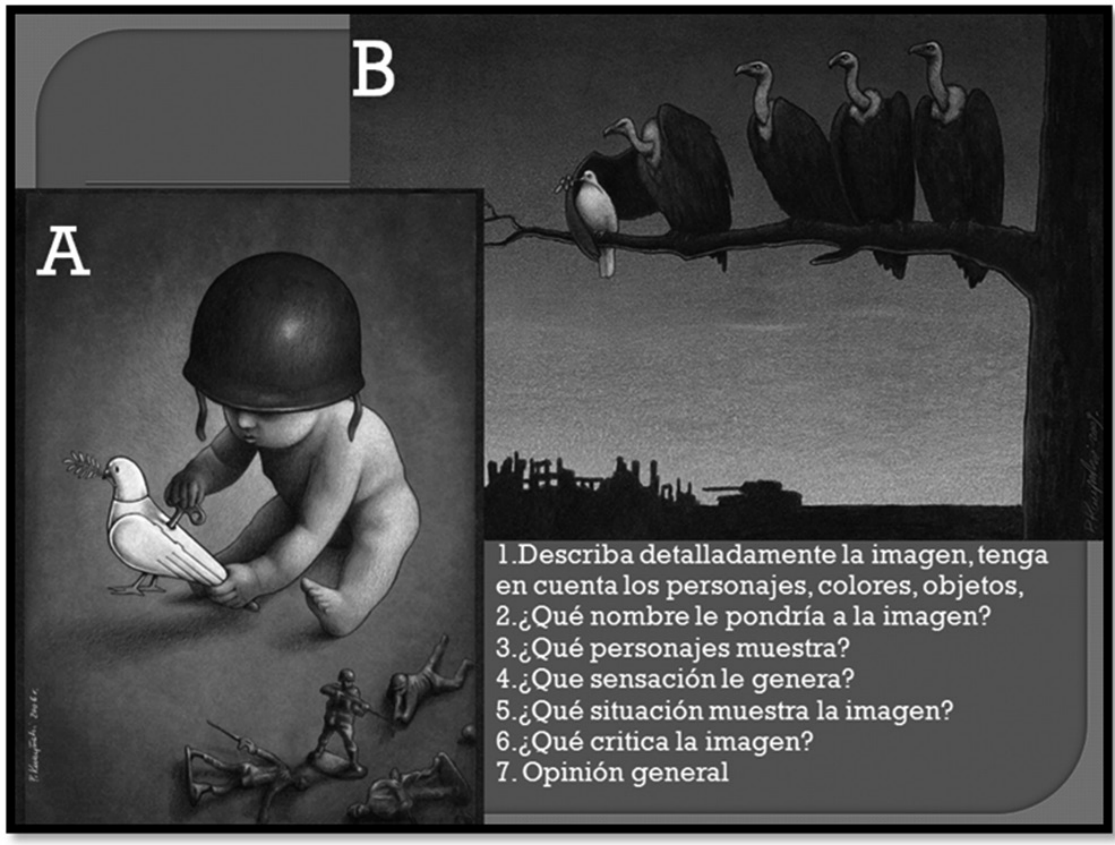

Taller análisis de imágenes. Obras de Pawel Kuczynski 


\section{Anexo D}

1) Descripción de imágenes

a) Personajes = Paloma de la paz, malas influencias

b) (ulores = Tonos rojzos

c) Ubjetus= arbol, ciuctades en guerra.

2) Numbre imagen

- Bex A la espalida de la paz se encuentra

3) Personajes

* Paloma de la paz

* Chulos

* Civelcia demolida

* tanciues cle guerra

4) Sensaciones -

* Tristezci, inconformiciad = Porque la inocencia cle una paloma seva cuando lleaden malas/ influencias o cucinaro a su espalda súlu existe guerra.

5) Situación ici inseguridaci, lavidenci cleseo de paz suprimiclo que tienen allgunas personas.

6) $\left(\mathrm{Hit}+\mathrm{CCCl}^{\mathrm{C}}\right.$

Critica que ion pocos los gue luchan para gue existar paz $y$ estos son rgnorados porgue quemprélexise guelra a dunae quiera

7) Opinión genercil=

pemuestra la guerra gue se da en todas partes y muestra con frialdaci el sentimiento reprimicio de la pre.

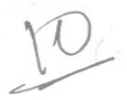

Respuesta del taller análisis de imágenes. Estudiante Valerie Paola Rojas, 9-01, IPN 


\section{Anexo E}

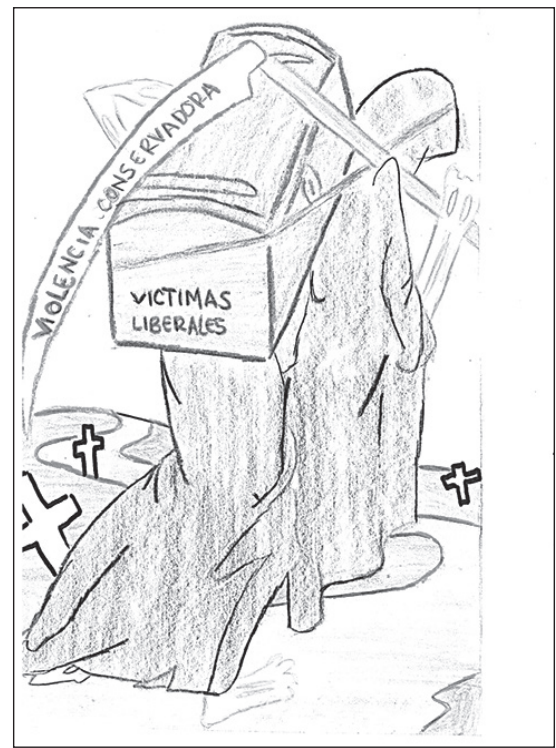

Trabajo final, estudiante Adriana Páez, 8-01, IPN

\section{Anexo F}

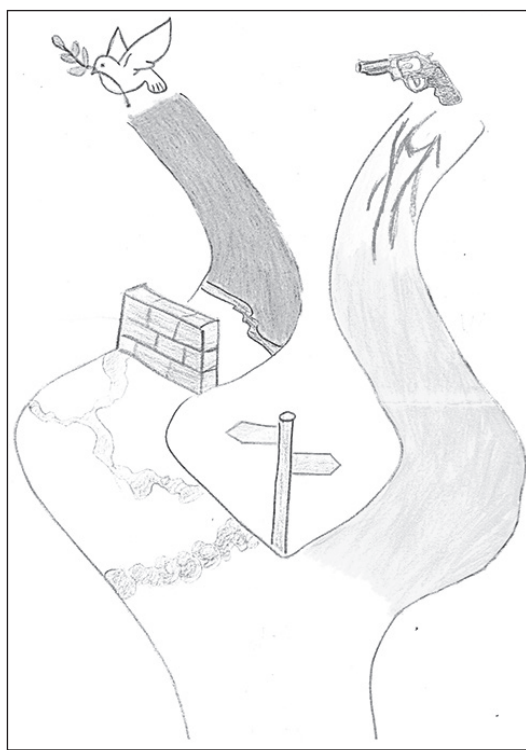

Trabajo final, estudiante Nicolás Vanegas, 9-01, IPN 


\section{Anexo G}

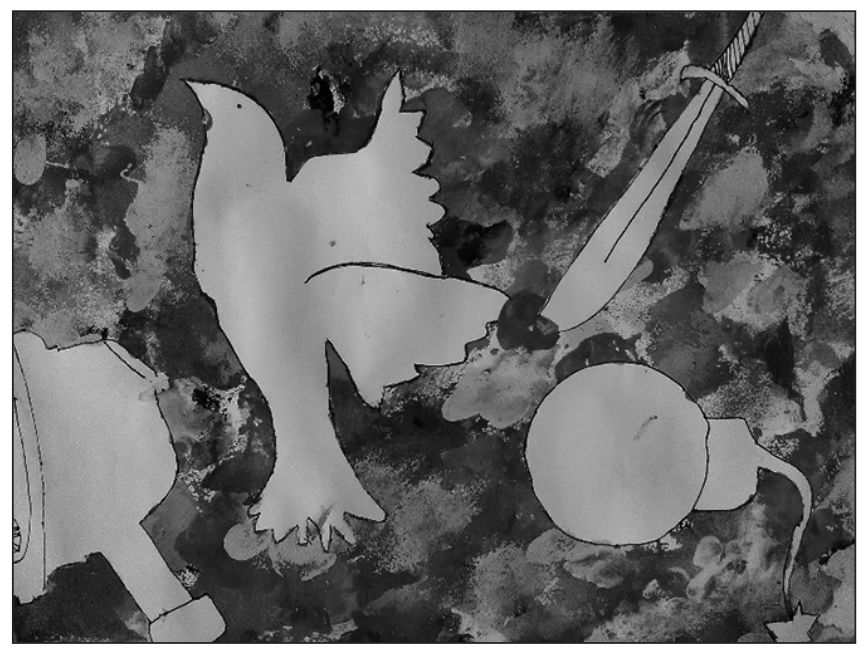

Trabajo final, estudiante Marlon Urrego, 9-02, IPN 